\title{
Employee Engagement: An Overview of the Literature on the Proposed Antithesis to Burnout
}

\author{
Yseult Freeney \& Joan Tiernan \\ UCD School of Psychology, University College Dublin, Ireland
}

\begin{abstract}
Two trends have emerged in burnout research that have resulted in a broadening of the topic. First, the concept of burnout has been expanded to embrace all professions, whereas it was previously considered to exist only in the human services. Second, in line with the growth of positive psychology, there has been a shift in focus toward its antithesis, namely engagement, which can be defined as a positive affective-motivational state of fulfilment in employees. As a new construct, the body of literature on this subject is limited. However, this paper offers a comprehensive review of the empirical findings that are available to date. It examines the origins of research on engagement and goes on to explore the likely antecedents and consequences of this construct. In doing so it highlights the value of engagement not only as a state of well-being but also as a predictor of high performance.
\end{abstract}

Which employee attitudes are most critical for performance and have most impact on the bottom line? Up until recently, it had been accepted that employee satisfaction was a key objective of organisations as - it was inferred this influences job performance. However, 'satisfied' employees do not necessarily perform to the best of their abilities. For instance, an employee who spends the workday on personal calls and e-mails could be satisfied with his or her job. However, this person is not likely to be productive. Researchers in the Gallup Organisation (a consulting group based in the US) now suggest that there are better indicators of performance and commitment to the organisation (e.g., Harter, Schmidt \& Hayes, 2002). One of the key indicators that has emerged from research in recent years is employee engagement. As the antithesis to burnout, it is believed that by building the type of environment where employees can become engaged, many of the problems associated with stress and dissatisfaction in the workplace can be overcome. In fact, employee engagement has become the new human resources buzzword, with organisations choosing to replace their traditional job satisfaction surveys with short questionnaires, such as the Gallup Q12 (See Harter et al, 2002). However, to date there has been little systematic academic research into the validity of the construct of engagement and the Q12 is certainly in need of scrutiny. This overview will define engagement and examine the academic research that is available on the topic.

\section{Burnout}

Job burnout is a psychological syndrome that results from a person-job misfit that involves exhaustion, cynicism and detachment from the job and a sense of ineffectiveness (Maslach, 2003). To some extent, it is like being depressed about work and having little energy and enthusiasm for the job. Burnout can be divided into the following three components. Emotional exhaustion is the feeling of fatigue and tiredness at work. Depersonalisation is the development of a cynical and uncaring feeling

Address correspondence to: Yseult Freeney, UCD School of Psychology, University College Dublin, Belfield, Dublin 4 Ireland email: Ms. Yseult Freeney, School of Psychology, University College Dublin, Belfield, Dublin 4, Ireland yseult.freeney@ucd.ie 
towards others. Reduced personal accomplishment is when an employee feels that they are not accomplishing anything worthwhile. Workers and social commentators identified burnout as a social problem long before it became of interest to academic researchers (Maslach, 2003). With regard to the discriminant validity of burnout, particularly in relation to depression, research has demonstrated how burnout is a work context-specific problem whereas depression encroaches on all aspects of an individual's life (Bakker et al., 2000).

The construct of burnout is complex. Some researchers have attempted to organise the research on burnout by formalising it as a model. One of the more recently proposed models, the Job Demands-Resources Model (JDR Model; Demerouti, Bakker, Nachreiner \& Schaufeli, 2001) will be reviewed here. This model is important in that it is the first in the burnout literature to refer to the concept of engagement.

Demerouti, Bakker, Nachreiner et al. (2001) define job demands as 'physical, social, or organizational aspects of the job that require sustained physical or mental effort and are therefore associated with certain physiological and psychological costs' (p. 501). The authors go on to define job resources as 'physical, psychological, social, or organisational aspects of the job' that allow for the attainment of work goals, contribute to the employee's personal growth and development and relieve the pressure of job demands... (p. 501). Such resources include job control, participation in decision-making, access to the necessary materials, feedback, reinforcement contingencies and support from colleagues. These resources bear a resemblance to the common coping strategies used to combat stress but are specific to the context of work. In short, the idea is that extreme job demands lead to exhaustion but that this relationship is complicated by the absence of sufficient resources to deal with these demands, resulting in disengagement from work. The JD-R model proposes that job demands eventually lead to burnout but that this process is mediated by access to job resources. Therefore, the long-term consequence of the constant pressure of job demands, coupled with a lack of job resources, is burnout or disengagement from work.

Maslach and Leiter (1997) argue that reducing the possibility of burnout is only part of the preventative approach. What is more important is increasing the chances that people remain engaged with their work and this means focusing on energy, involvement and effectiveness. The following section introduces this concept of engagement.

\section{Defining Engagement}

A decade or so before the concept of engagement emerged in the literature on burnout, it was considered by Kahn (1990), who argued that 'people can use varying degrees of their selves, physically, cognitively, and emotionally, in work role performances' ( $p$. 692). He describes engagement as the 'harnessing of organization members' selves to their work roles ... People employ and express themselves physically, cognitively and emotionally during role performances' (p. 694). At the other extreme, employees become disengaged when they withdraw from their role. Three psychological conditions emerged from Kahn's research that appear to influence the state of personal engagement:

1. Meaningfulness: This refers to a sense of return on investments of self in role performances. These returns might include feeling valued by the employer, having a job that provides challenges and variety, and good interpersonal relationships with colleagues on a professional and personal basis.

2. Safety: This is where an employee feels safe to show their self without the possibility of a negative impact to self-image, status or career. Much of this will depend on the trust and support available to employees at a managerial and organisational level.

3. Availability: This is a sense of feeling capable, physically, emotionally and psychologically, to invest in role performances. The concept of availability is similar to the idea put forward by Demerouti, Bakker, Nachreiner et al. (2001) that resources are necessary to deal with demands at work so that employees can become 
engaged. It also ties into the question of work-life balance. Kahn (1990) points out that issues in people's lives outside of work 'leave them more or less available for investments of self during role performances' (p. 705).

In addition, Kahn (1990) has defined a state of disengagement. This is where the employee withdraws from the work role physically, cognitively and emotionally. In a sense, it amounts to a removal of one's energy from the tasks at hand. Interestingly, at this early stage Kahn (1990) also likened the state of disengagement to Maslach's concept of burnout. Beyond this, however, more recent definitions of engagement bear few resemblances to Kahn's description.

Maslach and Leiter (1997) relabelled burnout as an erosion of engagement with the job. The authors characterise engagement as energy, involvement and efficacy. These are proposed as the direct opposites of the burnout dimensions of exhaustion, cynicism and lack of professional efficacy. Maslach and Leiter discuss burnout within the framework of six areas of organisational life which they return to in order to describe the conditions necessary for engagement. For Maslach, Schaufeli and Leiter (2001), engaged employees are persons who: (a) have a sustainable workload; (b) have feelings of choice and control; (c) feel they receive appropriate recognition and reward; (d) believe they have social support available to them in the workplace; (e) perceive the organisation to be fair and just; and (f) find their work meaningful. The last point above overlaps with Kahn's (1990) original definition of engagement.

Empirical support for this model of engagement comes from case studies of two hospital units carried out by Maslach and Leiter (1997). The employees in one of the units displayed a typical burnout profile, with unfavourable scores across these six areas. The second unit's profile of engagement was the opposite, displaying favourable scores to these factors, especially with regard to workload, control, fairness and meaningfulness. An interesting point about this case study was that a patient satisfaction survey was carried out concurrently by a consulting group. Patients in units where the staff were engaged were significantly more satisfied with the level of care than those in units where the staff were burned out (Maslach \& Leiter, 1997).

While Maslach (e.g. 2003) views engagement purely as the antithesis to burnout, others define it as a construct in its own right (Schaufeli \& Bakker, 2003 and the Gallup Organisation e.g. Harter et al., 2002). Even though Schaufeli still considers it to be at the opposite end of the spectrum from burnout, he describes engagement as a persistent, positive affectivemotivational state of fulfilment in employees that is characterised by vigour, dedication and absorption (Schaufeli \& Bakker, 2003). Furthermore, according to this approach, burnout is characterised by low levels of activation and pleasure, whereas engagement is characterised by high levels of activation and pleasure. While an engaged employee will not be experiencing burnout, an employee who is not burnt out may not be engaged. Engaged employees have a sense of energetic and effective connection with their work activities, and they perceive themselves as capable of dealing with the demands of their job (Schaufeli \& Bakker, 2003).

Vigour refers to high levels of energy and the willingness to invest time and effort in the job. In Schaufeli \& Bakker's (2003) definition engagement is described as a 'pervasive affective-cognitive state' and so does not incorporate a behavioural element. However, vigour involves investing effort into one's work and could be construed as a behavioural component. Dedication is similar to job involvement but is accompanied by a sense of pride and inspiration. It is not simply a cognitive or belief state but includes an affective element as well. Finally, the absorption element of engagement refers to the feelings of immersion in one's work whereby the employee does not notice time passing and can even have difficulties detaching from work. This would appear to be the affective element, although future research should explore possible behavioural, cognitive and affective substrates.

Qualitative interviews with engaged employees have revealed that they are active in 
work, taking initiatives and generating their own feedback (Schaufeli et al. as cited in Schaufeli \& Bakker, 2003). They report that their values match those of the organisation in which they are working and would even describe finding their work fun. Engaged employees - in contrast to ones who are burnt out - report experiences of tiredness as pleasant in that they feel a sense of accomplishment associated with it (Schaufeli et al. as cited in Schaufeli \& Bakker, 2003). This raises the possibility as to whether there are personality differences between people who experience burnout and engagement.

To date, there has been no research that has directly investigated how engagement relates to an individual's sense of self. No definition of engagement details whether it is a state (as determined by inputs from the work environment), or whether it is actually a trait (dependent on the personality of the individual). In other words, does the organisation create work environments that foster vigour, dedication and absorption? Or is it that some people are just energetic and dedicated and others are not, regardless of their work? Indeed, it may be a combination of both trait and state. The only aspect of the self that has been found to be positively related to engagement is selfefficacy (Salanova, Schaufeli, Llorens, Piero \& Grau as cited in Schaufeli \& Bakker, 2003). Clearly this question needs to be addressed as it has important implications for the development of successful interventions.

In summary, burnout is characterised by a combination of exhaustion and cynicism (low activation and low identification), while engagement is characterised by vigour and dedication (high activation and high identification). Although these two elements are direct opposites, the ultimate outcomes of reduced efficacy and absorption are not. Rather they are conceptually distinct (Schaufeli, Salanova, Gonzalez-Roma \& Bakker, 2002).

As noted in relation to the JD- $\mathrm{R}$ model of burnout (Demerouti, Bakker, Nachreiner et al., 2001), the important distinction is that burnout relates particularly to job demands, whereas job resources such as job control, availability of feedback and learning opportunities are more indicative of engagement. This is where there is considerable overlap with the research carried out by the Gallup Organisation (Harter et al., 2002).

Researchers in the Gallup Organisation define employee engagement as 'the individual's involvement and satisfaction with as well as enthusiasm for work' (Harter et al., 2002, p. 269). The engaged employee is someone who is $100 \%$ psychologically committed to their role. They thrill to the challenge of their work every day. They are in a role that uses their talents. They know the scope of their job and they are always looking for new and different ways of achieving the outcomes of their role. Harter et al. (2002) describe employees as emotionally and cognitively engaged when they know what is expected of them at work, when they have the necessary materials to carry out their work, perceive themselves to belong to the organisation and are given the opportunity to learn and develop within the organisation. The emphasis in this definition, then, is on inputs rather than on employees' attitudes or affective states. Once more, this definition leaves no room for the idea that engagement may be a trait. On the contrary, it stipulates that employee engagement relies solely on the inputs of the organisation, particularly from the immediate supervisor. Clearly, research into engagement should prioritise this question.

The definition of engagement put forward by Schaufeli and Bakker (2003) would appear to be the best available for of the following reasons. First, it taps into the nature of the state of engagement by considering cognitive and affective components. Second, its superiority lies in the fact that it further divides engagement into three components which can be considered independently, namely vigour, dedication and absorption. This allows for a more specific identification of where strengths and weaknesses lie in terms of levels of engagement. Future research into these composite elements may elucidate discrete paths of antecedents and consequences. If this is the case, it will support the development of more effective interventions allowing the identification of more specific areas in need of attention. This leads to the process of engagement. What are the causes and outcomes of an engaged workforce? Can organisations 
create engagement or does it depend on the individual employee?

\section{The Process of Engagement}

This section will review the research findings on employee engagement and its correlates. It will outline the various antecedents and consequences proposed by researchers working in the Gallup Organisation and those derived using the Utrecht Work Engagement Scale (UWES; Schaufeli, Salanova, Gonzalez-Roma \& Bakker, 2002).

The Gallup Organisation has concentrated on how managers can promote engagement. This perspective focuses on actions that occur in the workplace, such as how often feedback is given. It does not investigate the employees' feelings. As noted, this would be based on the idea that engagement is a state, open to intervention.

Developing from the research on burnout, extensive academic work has been carried out by Schaufeli and his colleagues (e.g. Schaufeli \& Bakker, 2003). This angle focuses more on the employees' feelings and attitudes, and considers the broader picture by viewing engagement as a process rather than simply a state. Both perspectives are loosely rooted in the following hypothesised model: employee engagement - a combination of cognitive and emotional antecedents - generates higher frequency of positive affect such as satisfaction and commitment, which in turn results in efficient application of work. As of yet, the directionality of such a model has not been confirmed empirically but a suggested diagram of how that model might appear is provided in Figure 1. In fact, it is likely that such a model would be circular in nature. While the former perspective seems to place a greater emphasis on how engagement affects productivity, the second framework places a stronger emphasis on employee well-being.

\section{Antecedents: Fostering Engagement}

Since the majority, if not all, of the studies in the area of employee engagement are crosssectional in nature, few causal inferences can be

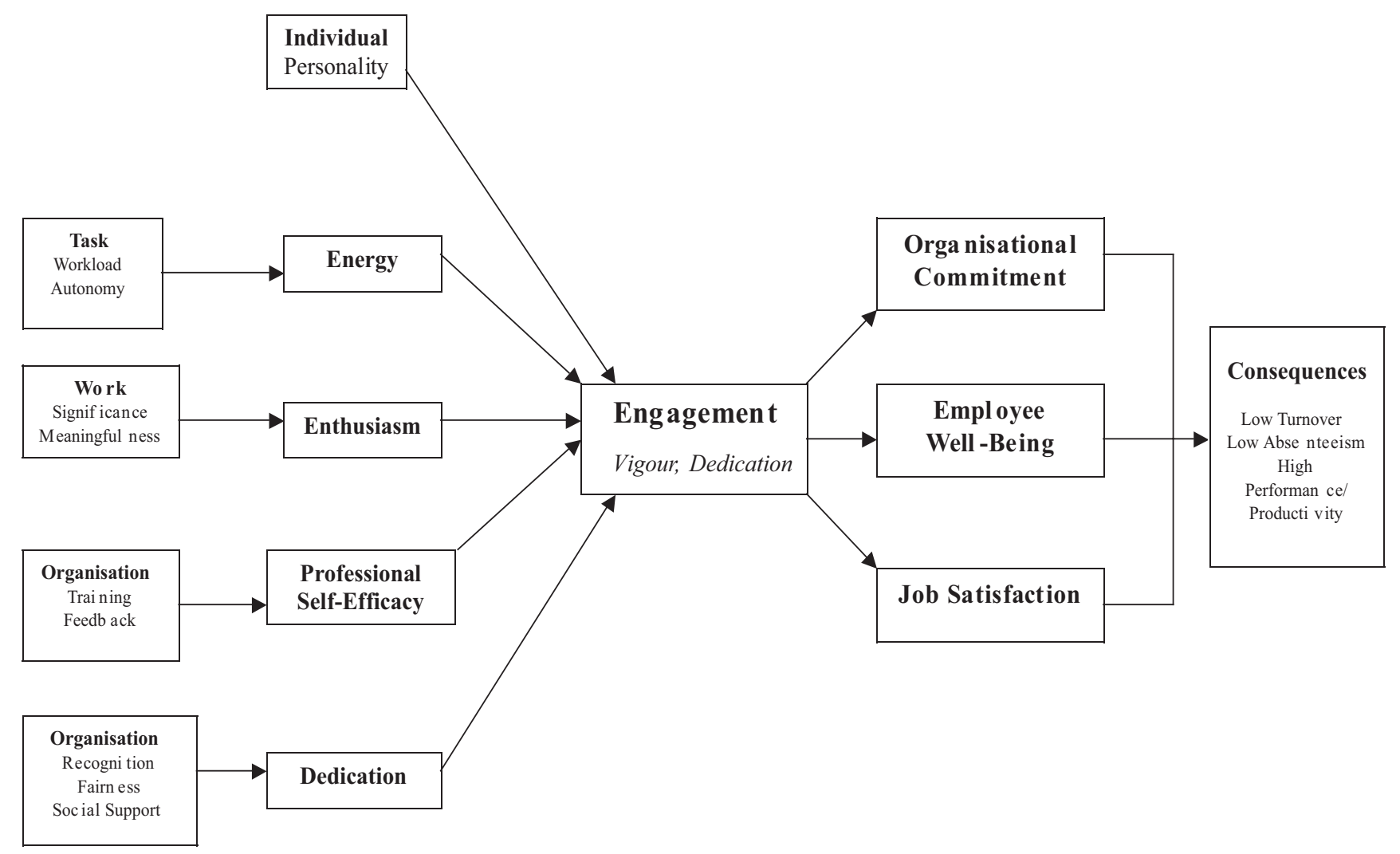

FIGURE. 1: 
TABLE 1.

Antecedents of Engagement and Disengagement under the Jobs Demands-Resources (JD-R) Framework

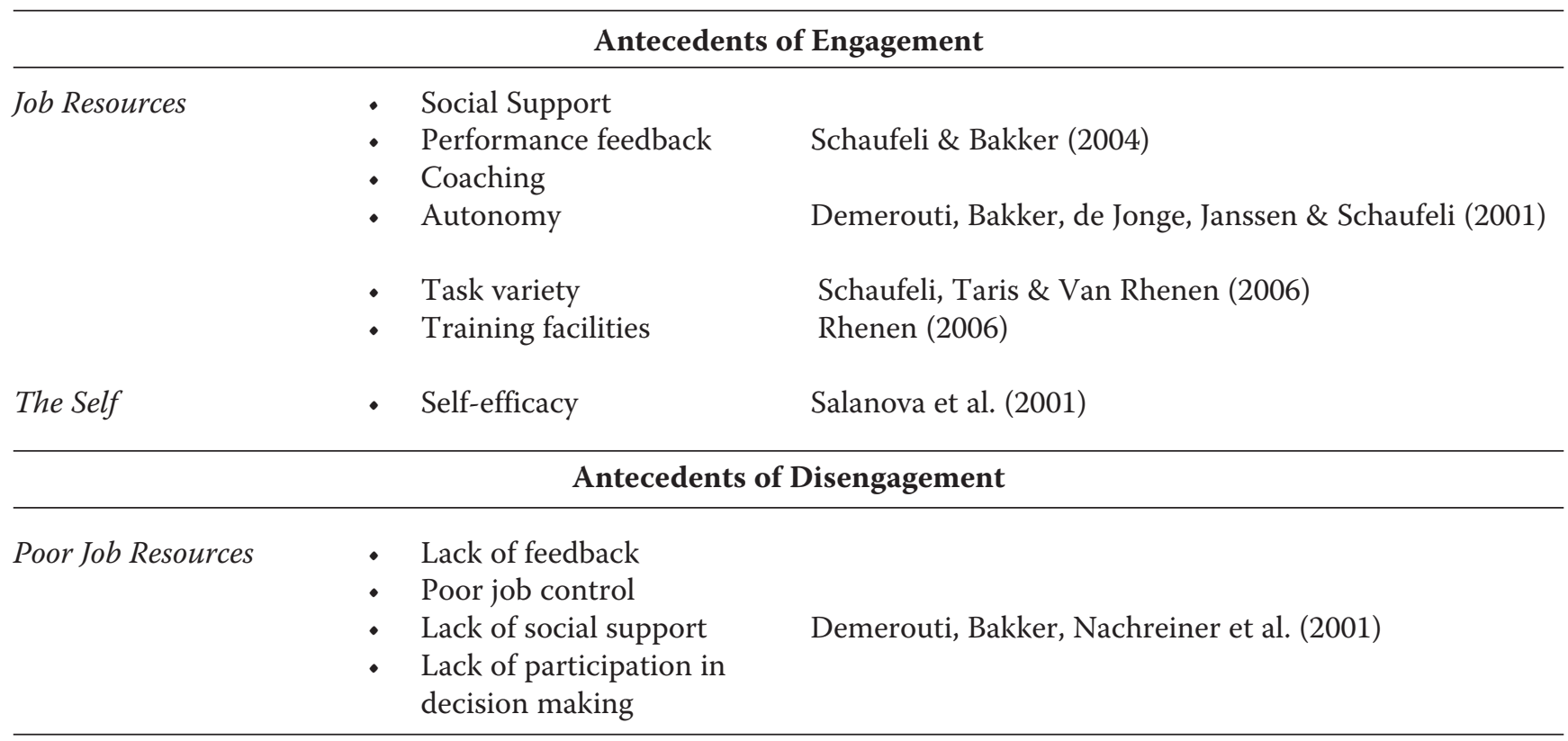

made with regard to the antecedents of engagement. Furthermore, research has not so far attempted to elucidate whether or not the three elements of engagement (i.e., vigour, dedication and absorption) have separate antecedents. However, the composite construct of engagement has been found to be positively associated with a number of other variables that are presented in Table 1 above.

Following the Gallup tradition, Harter, Schmidt and Keyes (2003) propose a model of engagement that is strongly influenced by Maslow's (1970) hierarchy of needs. In the model basic needs at work must be fulfilled before higher needs can be considered and this has implications regarding the antecedents of engagement. Starting at the bottom of the hierarchy (see Figure 2), basic needs involve clarity of expectations and the provision of basic materials (e.g., functioning PCs, faxes etc.) Moving beyond this, employees need to feel that they are contributing to the organisation, that they have opportunities to use their talents, and that they are receiving recognition and feedback for the work they do (Harter et al., 2003). In essence, this is akin to the notion of personenvironment fit, whereby the employee is matched to their organisation.

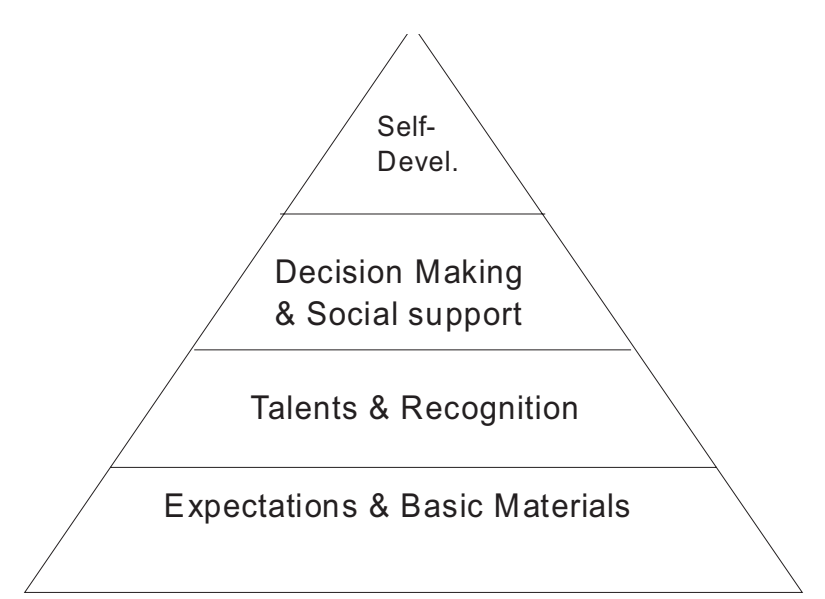

FIGURE 2

\section{Gallup Model of Engagement (Based on Maslow's [1970] Hierarchy of Needs)}

At the next level, employees need to feel a sense of belonging. This involves participative decision-making and having meaningful relationships with co-workers and supervisors. Such resources reinforce communication and creativity (Harter et al., 2003). The peak of this hierarchy - in line with Maslow's (1970) notion of self-actualisation - is self-development. For this to occur, employees need to be allowed to discuss their progress and to be given the 
opportunity to learn new skills and develop existing ones. When these factors come together, Harter et al. (2003) argue, they create the type of environment in which employees become engaged and, therefore, more productive.

\section{Consequences}

Research on the consequences of engagement is still in its infancy. Gallup (e.g., Harter et al., 2003) have published research supporting the idea that a more engaged employee is more profitable, more customer-focused, safer and more likely to withstand temptations to accept other job offers. Harter et al., (2003) discuss their model wherein employee engagement generates a higher frequency of positive affect. This in turn relates to the efficient application of work, employee retention, creativity and, ultimately, business outcomes such as high performance and productivity . In support of this theory, Gallup has conducted a number of studies using a measure it developed which is based on this model.

One such study carried out by Harter et al. (2002) found that employee engagement was associated with a range of business outcomes, such as higher levels of performance (.38) and customer-satisfaction and loyalty (.33), and lower levels of staff turnover (-.30). However, the importance of these findings needs to be interpreted cautiously in view of the relatively small size of the correlations. There are a number of issues regarding the measure used by Gallup (the Q12), which we will address below.

Examining the consequences of engagement as studied using the Utrecht Work Engagement Scale (UWES; Schaufeli et al., 2002) reveals some interesting results. Engagement has been found to relate to positive attitudes towards work and towards the organisation, job satisfaction, organisational commitment and low turnover intention (Demerouti, Bakker, De Jonge, Janssen \& Schaufeli, 2001; Salanova et al. as cited in Schaufeli \& Bakker, 2003). However, since this research is not longitudinal, no precise causal inferences can be made. Engagement has also been found to be linked to initiative and motivation (Sonnentag, 2003), and to organisational citizenship behaviour (Salanova,
Agut \& Piero, 2005). As the antithesis to burnout, which has been found to have negative effects on health, one would expect engagement to have positive influences on employee wellbeing. This has been documented by Schaufeli, Taris and Van Rhenen (In Press), with high levels of engagement being associated with low levels of depression and distress. Finally, Salanova et al. (2005) found that engagement was related to performance. Employees' levels of engagement had a positive impact on the service climate of hotels and restaurants, with an increase in the display of extra-role behaviour and an improvement in customer satisfaction. Another study found that engagement was positively related to academic achievement for university students across three countries (Schaufeli, Martinez, Marques-Pinto, Salanova \& Bakker, 2002).

\section{Returning to the JD-R Model}

Having considered the antecedents and consequences of engagement, it is a good point to return to the Job Demands-Resources model of burnout and engagement (Demerouti, Bakker, Nachreiner et al., 2001). Recent studies have explored the model in terms of the different paths of burnout and engagement. Schaufeli and Bakker (2004) tested the model in which burnout and engagement have different predictors and different consequences, resulting from two psychological processes. The first is the energetic process whereby job demands are linked to health problems through burnout. The second is the motivational process which links job resources to organisational outcomes (e.g., turnover intention) through engagement.

Schaufeli and Bakker (2004) found that burnout and engagement are indeed negatively related, and that burnout is mainly predicted by job demands but also by job resources. Job resources predicted engagement but no such association was observed for job demands. While burnout and engagement are negatively related, this study found that the two constructs do not lie at opposite ends of the same dimension but form two discrete negatively correlated dimensions. One interesting finding was that the Personal Efficacy (PE) dimension of the Maslach Burnout Inventory (MBI; Maslach 
\& Jackson, 1986) loaded on engagement rather than on burnout. In other words, PE would appear to be an element of engagement rather than burnout. Current research supports the proposal that the core dimensions of burnout (i.e., emotional exhaustion and cynicism) and of engagement (i.e., vigour and dedication) are opposites of each other but that they are also two distinct bipolar dimensions (GonzalezRoma, Schaufeli, Bakker \& Lloret, 2006). These dimensions have been named energy and identification.

While reducing demands is the most important factor for preventative organisationbased strategies, in relation to issues such as turnover, Schaufeli and Bakker (2004) only considered three job resources: feedback, social support and supervisory coaching. Conceivably, investigating additional resources (e.g., training and development) may elucidate the greater value of strategies that focus on increasing resources. Increasing job resources through training, participative management and improving social support networks are likely to lead to increased engagement. To that end, more investigation is required. In addition, the JD-R model may benefit from investigations of the relationship between engagement and anticipated outcomes such as organisational commitment and job performance.

As it stands, there is support for the JD-R model of burnout and engagement. Initial studies provide evidence for demands and resources working in independent paths (e.g., Montgomery, Peeters, Schaufeli \& Den Ouden, 2003). Bakker, Demerouti, Taris, Schaufeli and Schreurs (2003) also found strong evidence for the JD-R model. They found that job demands are primarily and positively related to the exhaustion component of burnout, whereas job resources are primarily and negatively related to cynicism and positively to professional efficacy. However, this study did not consider engagement directly.

In terms of consequences, Schaufeli and Bakker (2004) found that burnout was linked to health problems and turnover intention, while engagement was only found to be linked to turnover intention. A final finding of this study was that burnout mediated the relationship between job demands and health problems, while engagement mediated the relationship between job resources and turnover intention. The important implication of this study, Schaufeli and Bakker (2004) argue, is that different intervention strategies need to be implemented depending on whether the purpose is to reduce burnout or to build engagement.

\section{Can Work Engagement Be Discriminated From Other Established Concepts?}

Examining the research on engagement, striking resemblances with recognised concepts such as organisational commitment are apparent. For example, both concepts comprise a sense of attachment and dedication to one's work. It is beyond the scope of this paper to provide a comparison of engagement and all other similar concepts in the literature but a number of contrasts will be drawn. Considering researchers are still at the stage of validating engagement as a construct, it is surprising that few studies are concerned with discriminating it from established concepts like organisational commitment and job involvement.

One recent study (Hallberg \& Schaufeli, 2006) has attempted to address this gap, aiming to demonstrate that engagement can be seen as a distinct concept from job involvement and organisational commitment. All three concepts refer to a positive attachment to work but work engagement stresses the idea of optimal functioning so that - unlike job involvement and organisational commitment - it is strongly related to the health and well-being of the employee. Employee engagement also focuses more on the attitudes towards one's work rather than the organisation as a whole. While they were found to be closely related concepts, it was demonstrated that they only share between $12 \%$ and $21 \%$ of variance. This corroborates the theory that they are related but not to the extent that any of the constructs can be considered redundant. In addition, the constructs had different relationships with the other variables that were measured: health complaints, job factors, motivation and turnover intention. Job factors such as autonomy and feedback were higher where engagement and commitment 
were also high but they did not appear to be as significant where job involvement was concerned.

The question remains, however, as to how useful the construct of engagement is in the workplace. In relation to turnover intention, organisational commitment is a stronger negative predictor than engagement ( -.65 vs. -.40, Hallberg \& Schaufeli, 2006). In saying that, however, engagement is a stronger negative predictor of health outcomes (e.g., exhaustion, depressive symptoms, somatic complaints and sleep disturbances) than either job involvement or organisational commitment.

Perhaps most striking is the similarity of engagement to the idea of intrinsic motivation portrayed in Eby, Freeman, Rush and Lance's (1999) meta-analysis of the motivational basis of organisational commitment. These two ideas overlap particularly in relation to their proposed antecedents, although Eby et al. do not use the term engagement in their proposed framework. Returning to the antecedents of engagement as outlined in Table 1, Eby et al. also detailed many of these (i.e., task/skill variety, autonomy, feedback and supportiveness). Antecedents that do not overlap include the significance of training and coaching in the process of engagement (which was not considered in Eby et al.'s model), while the issue of fairness is not raised in the literature on engagement. However, this may stem from the fact that most of the literature on the causes of engagement is based around the JD-R model, focusing on the role job resources and, therefore, not necessarily including the issue of fairness.

Moreover, as stated earlier, Schaufeli and Bakker (2004), in proposing their extension of the JD- $\mathrm{R}$ model of burnout and engagement, discuss it in terms of two processes. The first one is the energetic process and it focuses on burnout. The second one is the motivational process and it links job resources via engagement with organisational outcomes such as turnover intention (Schaufeli \& Bakker, 2004). Clearly, this bears a resemblance to Eby et al.'s (1999) motivational basis to organisational commitment. This is particularly notable where Schaufeli and Bakker (2004) talk about job resources playing an intrinsic motivational role whereby they allow an employee to learn and develop in their job. In addition to intrinsic motivation, Schaufeli and Bakker (2004) also discuss how job resources may play an extrinsic motivational role because they facilitate the achievement of work goals among employees. This latter point is only a subtle difference and on its own cannot be taken to be sufficient to set engagement apart as a construct in its own right.

A key difference does exist between these two ideas, however, in that the concept of engagement - arising out of the literature on burnout - encompasses a sense of well-being to which the model proposed by Eby et al. (1999) makes no reference. Therefore, well-being would appear to be an important aspect of engagement that distinguishes it from more traditional constructs. Consequently, it is crucial that future research should focus on the health aspect of engagement, not only because it will further our understanding of it as a concept but it will set it apart from existing constructs like commitment, motivation and involvement, and perhaps in doing so will underline its value.

\section{Measurement Issues}

The fact that employee engagement is defined differently by different groups of researchers means that two instruments thus far have been developed in an attempt to measure the construct.

The Gallup Organisation has developed the Gallup Workplace Audit, or the Q12 which comprises 12 statements that measure employee perceptions of the quality of people-related management practices in their business units (The Gallup Organization, 1992-1999). While such measures would not usually be discussed in academic papers, it is important at this point to provide a critique of the Q12. Many large organisations in Ireland and around the globe use the Q12 or a similarly developed scale rather than scales that have been rigorously developed by academics. For this reason, it is important for those working in the field to be aware of the shortcomings of such scales when compared with more reliable measurements.

The Q12 is based on 30 years of accumulated quantitative and qualitative research, using focus groups and interviews with thousands of 
employees. The items on the Q12 measure processes and issues that are under the influence of the supervisor/manager. The items are loosely based on Maslow's (1970) hierarchy of needs, whereby the basic needs at work (e.g., having the materials to complete work) must be fulfilled before higher needs can be considered. There are no sub-dimensions to the overall scale and Gallup have not published details of the psychometric properties of the scale.

One major weakness with the Q12 is that it assumes that what precedes and encourages engagement for employees in the United States is the same for employees in all cultures. All of the items are centred on presumed antecedents of engagement, with no consideration of the employee's actual attitudes and feelings. It is conceivable that, even if high scores are attained on the Q12, employees in other cultures might not be feeling engaged because what is important for Americans might be less so for them. (Gallup does not give permission for their scale to be used for academic purposes)

The Utrecht Work Engagement Scale (UWES; Schaufeli \& Bakker, 2003; Schaufeli, Salanova et al., 2002) is a 17-item self-report questionnaire that includes the three aspects of work engagement: vigour, dedication and absorption. Many of the items are positively rephrased MBI-items. For example, 'When I get up in the morning, I feel like going to work' (vigour) versus 'I feel tired when I get up in the morning and have to face another day on the job' (exhaustion). The internal consistency of the three scales is good, with the majority of Cronbach's alpha values falling between .8 and .9 , and all exceeding the critical value of .7 (Nunnally \& Bernstein, 1994). The three dimensions of the UWES appear to be closely related, with inter-correlations between the three scales usually exceeding 65 (Demerouti, Bakker, de Jonge et al., 2001; Schaufeli, Salanova et al., 2002). The factor structure is mostly invariant across different countries (Schaufeli, Martinez et al., 2002). Thus, the UWES would appear to be a psychometrically sound measure of engagement.

On balance, then, the UWES would appear to be the superior of the measures of engagement that are available for the following reasons. First, it is a psychometrically sound measure, with very high reliability coefficients. Second, the UWES taps into the employees' attitudes about their work and organisation more than the Q12. The UWES assesses feelings and opinions rather than simply assuming that if the organisation is managed in a certain way, then all the employees will be engaged.

\section{CONCLUSIONS}

Engagement has been introduced as the antithesis to burnout. Research findings thus far support this but the precise relationship between the two constructs needs further elucidation. Recent research supports the proposal that the core dimensions of burnout and of engagement are opposites of each other but that they are also two distinct bipolar dimensions (Gonzalez-Roma et al., 2006). These dimensions have been named energy and identification.

In terms of fostering engagement, a number of antecedents were outlined. Longitudinal research in this area, particularly in relation to job resources, would greatly facilitate the development of effective intervention strategies. The consequences of engagement are the least investigated aspect and are in need of attention. One question in particular that deserves attention is whether engagement is a better a predictor of performance than job satisfaction. Furthermore, the three dimensions of engagement put forward by Schaufeli et al. (2002) need to be given more specific attention in terms of precisely how they combine to form engagement. Do employees need to score highly on all three dimensions? Is any one dimension more important than the other? Do they have separate paths in terms of antecedents and consequences?

Moreover, the issue of whether engagement is a state or a trait is clearly in need of further exploration since intervention strategies aimed at the organisational level are liable to be ineffective if engagement is something that lies within a person's personality. As suggested, it could be that engagement is rooted primarily in the personality of the employee and after that it depends upon the inputs of the organisation. This matter appears to be the one most in need 
of future research since it has important implications for the development of successful intervention programmes.

Unfortunately, any conclusions drawn here must remain provisional since research is at an early stage and longitudinal studies in particular are only currently underway. It would be premature to herald engagement as a substitute for the established concepts of job satisfaction and organisational commitment. Thus far, engagement has only been discriminated from organisational commitment and job involvement. To establish it as a valuable construct and to set it apart more clearly, it has been emphasised that future research should extend upon the well-being aspect of engagement.

Nonetheless, focusing on positive aspects of the employee-work relationship would seem a promising direction in which to take research. The idea of engagement, in essence, is about creating the type of environment that would take all parts of the well-being of an employee into consideration. It is about creating a workplace where employees can relate to and identify their work as an integral part of their life and not just as a source of income. If this theory can be put into practice, it is likely to benefit organisations greatly.

It is well documented that the consequences of burnout include ill health, absenteeism and poor performance (for a review, see Cordes \& Dougherty, 1993). A significant question that requires further investigation is whether engagement, as the antithesis of burnout, will be found to be positively related to good health, low absenteeism and good job performance. Thus far, no research has explicitly compared levels of engagement across different levels of performance. Also, it is not known whether engagement is created by the environment and climate of the organisation, or whether it is a personality trait that may not be amenable to alteration, leaving little scope for research on potential interventions. In relation to the JD-R model, further exploration of job resources such as social support and how they are related to engagement is required. While so much remains tentative, one point is certain: with employee engagement becoming the construct most in vogue in organisations, there is a need to validate it from an academic perspective.

\section{REFERENCES}

Bakker, A.B., Schaufeli, W.B., Demerouti, E., Janssen, P.M.P., Van der Hulst. R. and Brouwer, J. (2000). Using equity theory to examine the difference between burnout and depression. Anxiety, Stress and Coping: An International Journal, 13, 247-268.

Bakker, A.B., Demerouti, E., Taris, T.W., Schaufeli, W.B. \& Schreurs, P.J.G. (2003). A multigroup analysis of the job demandsresources model in four home care organizations. International Journal of Stress Management, 10, 16-38.

Cordes, C.L. \& Dougherty, T.W. (1993). A review and integration of research on job burnout. Academy of Management Review, 18, 621-656.

Demerouti, E., Bakker, A.B., de Jonge, J., Janssen, P.P.M. \& Schaufeli, W.B. (2001). Burnout and engagement at work as a function of demands and control. Scandinavian Journal of Work, Environment and Health, 27, 279-286.

Demerouti, E., Bakker, A.B., Nachreiner, F. \& Schaufeli, W.B (2001). The job demandsresources model of burnout. Journal of Applied Psychology, 86, 499-512.

Eby, L.T., Freeman, D.M., Rush, M.C. \& Lance, C.E. (1999). Motivational bases of affective organizational commitment: A partial test of an integrative theoretical model. Journal of Occupational and Organizational Psychology, 72, 463-483.

Gonzalez-Roma, V., Schaufeli, W.B., Bakker, A. \& Lloret, S. (2006). Burnout and engagement: Independent factors or opposite poles? Journal of Vocational Behaviour, 68, 165-174.

Hallberg, U. \& Schaufeli, W.B. (2006). Same same but different: Can work engagement be discriminated from job involvement and organizational commitment? European Psychologist, 11, 119-127.

Harter, J.K., Schmidt, F.L. \& Hayes, T.L. (2002). Business-unit level relationship between employee satisfaction, employee engagement, and business outcomes: A 
meta-analysis. Journal of Applied Psychology, 87, 268-279.

Harter, J.K., Schmidt, F.L \& Keyes, C.L.M. (2003). Well-Being in the workplace and its relationship to business outcomes: A review of the Gallup studies. In C.L.M. Keyes \& J. Haidt (Eds.), Flourishing: Positive psychology and the life well-lived (pp. 205-224). Washington, DC: American Psychological Association.

Kahn, W.A. (1990). Psychological conditions of personal engagement and disengagement at work. Academy of Management Journal, 33, 692-724.

Maslach, C. \& Jackson, S.E. (1986). Maslach Burnout Inventory ( $2^{\text {nd }}$ ed.). Palo Alto, CA: Consulting Psychologists Press.

Maslach, C. \& Leiter, M.P. (1997). The truth about burnout. San Francisco: Jossey-Bass.

Maslach, C., Schaufeli, W.B. \& Leiter, M.P. (2001). Job burnout. Annual Review of Psychology, 52, 397-42.

Maslach, C. (2003). Job Burnout: New directions in research and intervention. Current Directions in Psychological Science, 12, 189-192.

Maslow, A. (1970). Motivation and personality. New York: Harper and Row.

Montgomery, A.J., Peeters, M.C.W., Schaufeli, W.B. \& Den Ouden, M. (2003). Work-home interference among newspaper managers: Its relationship with burnout and engagement. Anxiety, Stress and Coping, 16, 195-211.

Nunnally, J.C. \& Bernstein, I.H. (1994). Psychometric theory ( $3^{\text {rd }}$ ed.). New York: McGraw-Hill.

Salanova, M., Agut, S. \& Piero, J.M. (2005). Linking organisational facilitators and work engagement to employee performance and customer loyalty: The mediation of service climate. Journal of Applied Psychology, 90, 1217-1227.

Schaufeli, W.B. \& Bakker, A.B. (2003). Utrecht Work Engagement Scale: Preliminary manual (Version 1). Unpublished manuscript, Occupational Health Psychology Unit, Utrecht University, The Netherlands.

Schaufeli, W.B. \& Bakker, A.B. (2004). Job demands, job resources, and their relationship with burnout and engagement: A multi-sample study. Journal of Organizational Behaviour, 25, 293-315.

Schaufeli, W.B., Martinez, I., Marques-Pinto, A., Salanova, M. \& Bakker, A.B. (2002). Burnout and engagement in university students: A cross national study. Journal of Cross Cultural Psychology, 33, 464-481.

Schaufeli, W.B., Salanova, M., Gonzalez-Roma, V. \& Bakker, A.B. (2002). The measurement of engagement and burnout: A confirmative analytic approach. Journal of Happiness Studies, 3, 71-92.

Schaufeli, W.B., Taris, T.W. \& Van Rhenen, W. (In Press). Workaholism, burnout and engagement: Three of a kind or three different kinds of employee well-being? Applied Psychology: An International Review.

Sonnentag, S. (2003). Recovery, work engagement, and proactive behaviour: A new look at the interface between nonwork and work. Journal of Applied Psychology, 88, 518528.

The Gallup Organization. (1992-1999). Gallup Workplace Audit (Copyright Registration Certificate TX-5 080 066). Washington, DC: U.S. Copyright Office. 